\title{
Laryngeal Ulceration in Behcet's Disease
}

\author{
Is rafil Orhan, Fahrettin Yilmaz, Mehmet Eken
}

\begin{abstract}
Behcet's disease is a multisystem inflammatory disorder of unknown origin, characterized by recurrent oral and genital ulcerations, ocular and cutaneous lesions, arthritis, central nervous system and vascular disease. There is no pathognomanic laboratory test, but there are clinical criteria to assist in establishing the diagnosis.

There are only a few study about the laryngeal manifestation of Behcet's disease in the literature. We describe the case of a patient in whom epiglottic ulcers developed 7 years after the diagnosis of Behcet disease.
\end{abstract}

Keywords: Behcet's disease, Larynx, Epiglottic ulcers.

How to cite this article: Orhan I, Y ilmaz F, Eken M. Laryngeal Ulceration in Behcet's Disease. Int J Phonosurg Laryngol 2012;2(1):49-51.

\section{Source of support $\mathrm{Nil}$}

\section{Conflict of interest: None}

\section{INTR ODUCTION}

Behcet's disease (BD) is a multisystem, inflammatory disorder of unclear etiology that is characterized by recurrent oral and genital ulcers, skin lesions and uveitis. ${ }^{1}$ The etiology and pathogenesis of BD are not clear but are presumed to be multifactorial, involving genetic, infectious and immunological factors. ${ }^{1,2}$

B ehcet's disease is common in M editerranean countries and the far East; especially K orea and J apan. The condition is associated with the HLA B 51 gene. V asculitis is a major, and possibly the primary, feature of $B D .^{2}$

The clinical course of $B D$ is characterized by exacerbation and remission of unpredictable duration and frequency. However, the severity of symptoms and signs generally diminishes with time. ${ }^{1}$

The manifestations include arthritis, a positive pathergy test, thrombophlebitis, central nervous system disease and gastrointestinal ulcerations were seen in BD..$^{1,2}$ In spite of these there are only a few studies about the laryngeal manifestation of $B D$ in the literature.

We describe the case of a patient approval by the Local Ethics Committee in whom epiglottic ulcers developed 7 years after the diagnosis of B ehcet disease.

\section{CASE REPORT}

A 40-year-old female who had BD for 7 years complained of sore throat and dysphagia was referred to our clinic from dermatology service. She reported recurrent episodes of oral and genital ulcers. Physical findings consisted of arthritis involving both knees; scars of healed ulcers on the vulva; and pseudofolliculitis over the torso, thighs and legs. The pathergy test was positive. No evidence of destruction was seen on radiographs of the painful joints. Examination by an ophthalmologist found evidence of active uveitis.

L aboratory tests showed ery throcyte sedimentation rate elevation to $62 \mathrm{~mm} / \mathrm{h}$ and high levels of gammaglobulins alpha 1 (7 gm/l), alpha $2(14 \mathrm{gm} / \mathrm{l})$ and gamma (18 gm/l). His white blood cell count was $10.2 \times 10^{9} / l$. The patient reported no history of any systemic diseases except BD.

A fter otolaryngology consultation fibersoptic examination of the larynx revealed epiglottic ulcers. The epiglottis was edematously folded, occluding the larynx (Fig. 1). The surrounding supraglottic structures, including the aryepiglottic folds xand false vocal cords, were edematous. The vocal folds were found to be normal in motility. The subglottic area and upper trachea were normal with no edema or stricture (Fig. 2).

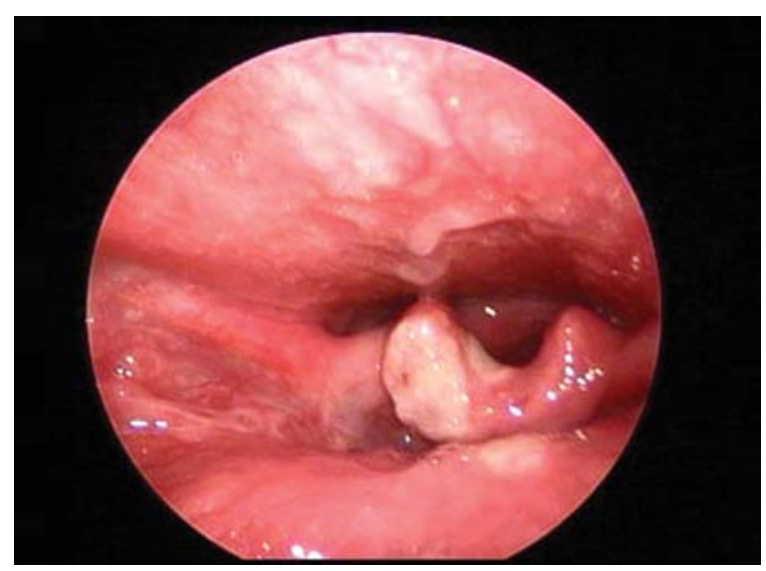

Fig. 1: The epiglottis was edematously folded, occluding the larynx, and the ulcerations were seen on epiglottis

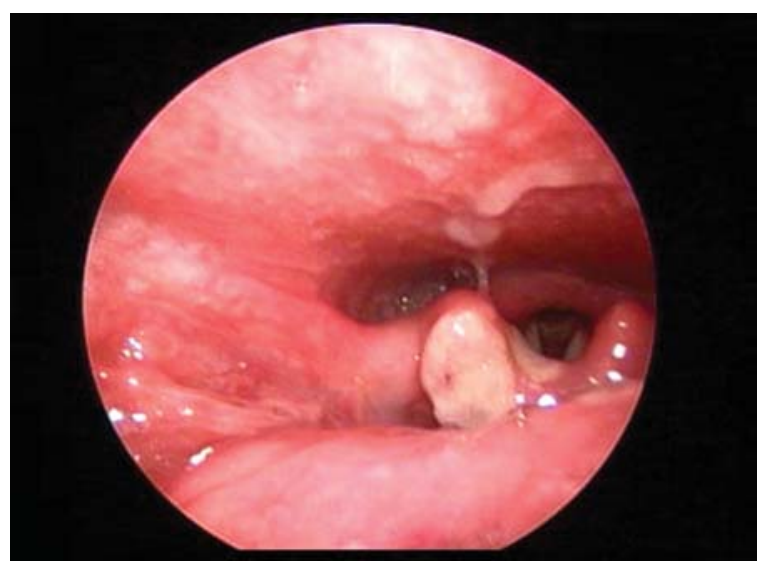

Fig. 2: Fiberoptic examination of the larynx at admission. The epiglottis was remarkably swollen. The vocal folds were found to be normal in motility 
The treatment was colchicine $1 \mathrm{gm} / \mathrm{dl}$, indomethacin $100 \mathrm{mg} / \mathrm{d}$ and prednisone $10 \mathrm{mg} / \mathrm{d}$. We added sprey with xylocain and corticosteroid to this treatment. One week later repeated fiberscopic examination of the larynx demonstreated reduced swelling of the epiglottis and its surrounding structures. The epiglottic ulcers were completely heal ed with no evidence of residual damage.

\section{DISCUSSION}

Behcet's disease was first described in 1937 by a Turkish dermatologist Dr Hulusi B ehcet from Istanbul as a triad of symptoms consisting of oral aphthae, genital ulcers and hypopyon uveitis. ${ }^{3}$

Behcet's disease is a systemic vasculitis of small and large vessels, of both the venous and arterial side. ${ }^{3,4}$ $V$ asculitis is a major characteristic of $B D$ and may be the primary pathologic feature. As an increased prevalence of neutrophils and immune complexes has been observed in the circulation, these may be important mediators of the vascular damage. ${ }^{2}$ The etiology of BD is uncertain. Genetic, environmental, virologic, bacterial and immunologic factors have been proposed as causative agents. ${ }^{5}$

There are 3 key features of $\mathrm{BD}$ : Recurrent oral ulcers, genital ulcers and ocular disease. ${ }^{3,6}$ Oral ulcers are usually the earliest sign of disease and may precede the onset of systemic symptoms by many years. Oral ulcers are similar to common mouth ulcers in appearance and localization, although they may be more extensive and painful, evolving quickly from a flat ulcer to a large sore. Lesions may occur singly or in crops and subside without scarring. The most common sites of oral ulceration are the tongue, lips and gingival and buccal mucosa, although involvement of the palate, pharynx and tonsil can also occur. ${ }^{7}$ Interestingly, the place of ulcer was epiglottis in our case.

Genital ulcers occur in 72 to $94 \%$ of cases and are morphologically similar to oral ulcers but frequently heal by scarring. In males, they most commonly occur on the scrotum and penile lesions are uncommon. In females, ulcers occur on the vulva, vagina and cervix and may cause dyspareunia. ${ }^{7} 0$ ur patient had genital ulcer too and the ulcer was placed on vulva.

Ocular disease is commonly bilateral and usually occurs 2 to 3 years after theonset of B D symptoms; it is the presenting feature in 10 to $20 \%$ of patients. The typical ocular involvement is a chronic, relapsing bilateral nongranulomatous uveitis that may involve the anterior segment, the posterior segment or both (panuveitis). Other ocular manifestations include iridocyclitis, keratitis, episcleritis, scleritis, vitritis, vitreous hemorrhage, retinal vasculitis, retinal vein occlusion, retinal neovascularization and optic neuritis. ${ }^{8} \mathrm{~W}$ hen we researched thefile, we saw that our patient had anterior uveitis.

The diagnosis of $B D$ is based on clinical criteria; no pathognomonic laboratory findings exist. Classification criteria (of the international study group for BD) used for patients participating in research protocols depend on the presence of recurrent oral ulceration, the hallmark of this disease, plus any two of the following: Recurrent genital ulcerations, ocular lesions (anterior or posterior uveitis, or cells in vitreous or slit lamp examination, or retinal vasculitis), typical skin lesions and a positive pathergy (skin hyperreactivity) test. ${ }^{1,5}$ There are no laboratory findings specific for $\mathrm{BD}$. There may be an increase in inflammatory parameters, such as $\mathrm{C}$-reactive protein, erythrocyte sedimentation rate, peripheral leukocytes and platel et counts during the active phase of the disease. ${ }^{6}$ The prognosis of $B D$ is mainly influenced by ocular, neurological or vascular manifestations. $1,7,9,10$

Therapy for BD largely depends on the signs, symptoms and severity of the disease. Although there is no standard therapy because the pathogenetic mechanism is unknown, a great deal of progress has been made in the management of this condition. ${ }^{2}$ Drugs that have been used include colchicine, nonsteroidal anti-inflammatory drugs, corticosteroids, dapsone, thalidomide, penicillin, acyclovir and interferon- $\alpha{ }^{1,5} \mathrm{M}$ ain goals of treatment are relieving symptoms, achieving a rapid resolution of inflammation, preventing or limiting tissue damage, reducing frequency and severity of attacks and avoiding complications. ${ }^{6}$

\section{CONCLUSION}

The possibility of laryngeal ulcerations should always be considered in cases of BD. Even when no airway obstruction is initially detected, larynx and especially the epiglottis must be examined, preferably with a laryngeal fiberscope. It is our hope that this case report will heighten the awareness of physicans, a possibility that must be kept in mind at all times when treating any patient with B ehcet disease.

\section{REFERENCES}

1. Houman $M H$, Hamzaoui $K$. Promising new therapies for B ehcet's disease. Eur J Intern M ed 2006;17:163-69.

2. Calamia KT, Wilson FC, Icen M, Crowson CS, Gabriel SE, $\mathrm{K}$ remers $\mathrm{HM}$. Epidemiology and clinical characteristics of B ehçet's disease in the US: A population-based study. A rthritis Rheum 2009;61:600-04.

3. Evereklioglu C. Current concepts in the etiology and treatment of Behçet disease. Surv Ophthalmol 2005;50:297-350.

4. Y urdakul S, Y azici H. B ehçet's syndrome. Best Pract R es Clin Rheumatol 2008;22:793-809. 
5. Onder M , G ürer M A. B ehçet's disease: A n enigmatic vasculitis. Clin Dermatol 1999;17:571-76.

6. M endes D, Correia M, B arbedo M, V aio T, M ota M , G onçalves $O$, et al. B ehçet's disease- a contemporary review. J A utoimmun 2009;32:178-88.

7. M arshall SE. B ehçet's disease. B est Pract R es Clin R heumatol 2004;18:291-311.

8. Kesen M R, Goldstein DA, Tessler HH. U veitis associated with pediatric B ehçet disease in the american midwest. A $\mathrm{m} J$ Ophthalmol 2008;146:819-27.

9. Tunes RS, A morim R, Santiago M B. Clinical aspects of Behcet's syndrome in Brazil: A review of 16 cases. Acta Reumatol Port 2009;34:235-40.

10. Siva A, Saip $S$. The spectrum of nervous system involvement in Behçet's syndrome and its differential diagnosis. J Neurol 2009;256:513-29.

\section{ABOUT THE AUTHORS}

\section{Israfil Orhan (Corresponding Author)}

Specialist, Department of Otorhinolaryngology, Istanbul M edipol University M edical Faculty, Istanbul, Turkey, Phone: + 90-212-631 20-50, Fax: + 90-212-631-17-95, e-mail: israfil.orhan@ mynet.com

\section{Fahrettin Yilmaz}

Associate Professor, Department of Otorhinolaryngology, Istanbul M edipol Hospital, Istanbul, Turkey

\section{Mehmet Eken}

Associate Professor, Department of Otorhinolaryngology, Istanbul Medipol Hospital, Istanbul, T urkey 